\title{
APRENDIZADOS NAS ENTRELINHAS: REFLEXÕES E OLHARES FEMININOS NO TRABALHO ETNOBIOLÓGICO
}

\section{LEARNING BETWEEN THE LINES: FEMININE THOUGHTS AND VIEWS IN DOING ETHNOBIOLOGY}

\author{
Graziela Dias BLANCO ${ }^{1 *}$, Sofia ZANK ${ }^{1}$, Daniele CANTELLI ${ }^{1}$, Bruna da SILVA ${ }^{1}$, Suelen Maria Beeck da \\ CUNHA $^{1}$, Maiara Cristina GONÇALVES ${ }^{1} \&$ Natalia HANAZAKI ${ }^{1}$ \\ ${ }^{a}$ Universidade Federal de Santa Catarina, Departamento de zoologia e ecologia, Laboratório de Ecologia Humana e etnobotânica, \\ Florianópolis, Brasil. \\ "contato: graziblanco@gmail.com
}

Submitted: 05/11/2020; Accepted: 03/02/2021; Published: 20/04/2021

\section{RESUMO}

Apresentamos neste ensaio um pequeno conjunto de relatos de caso recolhidos entre um grupo de pesquisadoras do Laboratório de Ecologia Humana e Etnobotânica da Universidade Federal de Santa Catarina. São casos observados ao longo de 15 anos de experiências de campo e fora dele, em torno do universo da pesquisa científica, que envolve pessoas como sujeitos/as/es em várias facetas do trabalho acadêmico. Relatamos experiências de campo que mostraram os desafios das pesquisadoras e das entrevistadas, e a força e o poder de mulheres na luta e na gestão de recursos e cuidado da comunidade, mas que muitas vezes permanecem invisíveis. Refletimos também sobre as dificuldades de lidar com situações de machismo ou micromachismo nas comunidades que trabalhamos. Nossos relatos provêm de experiências com mulheres comuns e com lideranças comunitárias; agricultoras; indígenas; pescadoras; quilombolas; mulheres do trabalho do lar e de fora dele. Mulheres de diferentes saberes e fazeres e que diariamente enfrentam uma luta em comum, ser mulher, incluindo também nossas experiências como mulheres e pesquisadoras na área acadêmica. Entre entrevistas, observações e aprendizados, proporcionamos narrativas para somar aos questionamentos e reflexões de pesquisadoras(es) no campo das etnociências.

PALAVRAS-CHAVE: Comunidades tradicionais, Desigualdade de gênero, Machismo, Mulheres na ciência, Pesquisadoras.

\begin{abstract}
In this essay, we present a small set of case reports collected among a group of researchers from the Laboratory of Human Ecology and Ethnobotany at the Federal University of Santa Catarina. These are cases observed over 15 years of field experience and outside, around the universe of academic research, which involves people as subjects in various facets of academic work. We report field experiences that showed the challenges of the researchers and the interviewees, and the strength and power of women in the struggle and in the management of resources and care of the community, but which often remain invisible. We also reflected on the difficulties of dealing with situations of machismo or micro-machismo in the communities where we work. Our reports come from experiences with ordinary women and community leaders; female farmers; indigenous people;
\end{abstract}


fisherwomen; quilombolas; women working at home and outside. Women of different knowledge and practices and who daily face a common struggle, being a woman, also including our experiences as women and researchers in the academic area. Between interviews, observations, and learning, we provide narratives to add to the questions and reflections of researchers (s) in the field of ethnosciences.

KEYWORDS: Traditional communities, Gender inaequality, Machism, Women in Science Researchers.

\section{INTRODUÇÃO}

A ciência ocidental é um espaço que tem sido ocupado em sua maioria pelo gênero masculino ao longo da história (NOGUEIRA, 2006), reflexo da sociedade heteronormativa e patriarcal que reforçou, ao longo do tempo, a imagem de uma identidade masculina como superior à feminina ou a de outros gêneros (BORGES et al., 2013). A conquista destes espaços de fazer ciência pelas mulheres foi, e ainda é, um desafio na maioria das áreas do conhecimento, desde a formação acadêmica até o mercado de trabalho (NOGUEIRA, 2006; ALPAY et al., 2010; TAI e BAGOLIN, 2019). No âmbito da pesquisa científica, o Brasil é um dos países com maior representatividade feminina (DA SILVA et al., 2019), mas isso infelizmente não equivale dizer que a desigualdade de gênero está diminuindo. Que iniciativas estão sendo aplicadas de forma a garantir uma maior equidade de gêneros dentro da pesquisa no Brasil? As desigualdades de gênero que permeiam nossa cultura muitas vezes acabam dificultando o desenvolvimento da pesquisa realizada pelas mulheres, e apresentam muitas lacunas ainda não resolvidas (DA SILVA et al., 2019; TAI e BAGOLIN, 2019).

Ainda que o número de mulheres na graduação e pós-graduação seja maior que o número de homens, esta realidade não se reproduz nas escalas seguintes, como na contratação de professoras e em cargos de gestão (GUEDES, 2008; ALPAY et al., 2010; CAPES, 2017). E para mulheres pretas ou pardas, a diferença é ainda maior, sendo de duas a três vezes menor a sua representatividade nestes cargos, quando comparadas com as mulheres brancas (VIEIRA, 2018). Os desafios enfrentados por pesquisadoras durante o processo de pesquisa ainda não são devidamente debatidos neste ambiente de trabalho (GUEDES, 2008). Em áreas da pesquisa, como a etnobiologia, que envolve entrevistas, ida a campo e contato com diferentes grupos humanos e culturas de múltiplos saberes, alguns desafios se acrescentam à realidade das pesquisadoras (DA SILVA et al., 2019). Nestes momentos observamos e sofremos com os efeitos negativos que a desigualdade de gênero 
BLANCO, G. D. et al. Aprendizados nas entrelinhas: reflexões e olhares femininos no trabalho etnobiológico. Ethnoscientia v.6 n. 2, especial, 2021. DOI: 10.22276/ethnoscientia.v6i2.368

produz, não só para as pesquisadoras, mas também, com as mulheres que conhecemos e entrevistamos (GUEDES, 2008; ALPAY et al., 2010; DA SILVA et al., 2019).

Nas últimas décadas, a representatividade das mulheres como lideranças tem crescido nas comunidades tradicionais e sua atuação, dentro e fora das comunidades, tem ganhado destaque (FREITAS e PERREIRA, 2017). Em 2015, foi assinado por 150 chefes de Estado os 17 objetivos para alcançarmos um mundo mais justo e sustentável (ONU, 2015). Entre estes, o $5^{\circ}$ objetivo aborda a urgência da igualdade entre gêneros, através de maior representatividade e reconhecimento das mulheres no âmbito social e político na sociedade (ONU, 2015). Entretanto, apesar do crescimento da última década na representatividade e do reconhecimento mundial de urgência pela equidade de gênero, os desafios e estruturas culturais que permeiam as comunidades tradicionais e da ciência, ainda não foram totalmente compreendidos e superados (BAUER, 2016; FREITAS e PERREIRA, 2017; DA SILVA et al., 2019). Mulheres que são lideranças políticas em suas comunidades ainda desempenham diversas outras funções sociais, que muitas vezes não são devidamente reconhecidas, são invisíveis ou não são estudadas por não serem tradicionalmente associadas a um "saber feminino" (FREITAS e PERREIRA, 2017; BORGES, et al., 2013).

A desigualdade de gênero é uma construção sociocultural e plural, ou seja, a desigualdade de gênero vai além da desigualdade apenas entre homens e mulheres, e está interligada com as origens culturais das sociedades (DESCARRIES, 2000; PATAI, 2010; BORGES et al. 2013). Ela se expressa de formas distintas entre mulheres brancas, pretas e pardas, trans, indígenas e de distintas origens étnicas (PATAI, 2010), com pautas, lutas e desafios diferentes para cada grupo (DESCARRIES, 2000; PATAI, 2010). Por esta razão, como pesquisadoras da área da etnobiologia, nos deparamos com diferentes níveis de desigualdade de gênero, hora como protagonistas, hora como telespectadoras. A desigualdade de gênero no nosso campo de trabalho pode se manifestar de forma direta, através de práticas de machismo como o desrespeito durante uma entrevista ou pelo medo de realizar o campo e entrevistas sozinhas, devido aos assédios sofridos ou que podem ocorrer (GUEDES, 2008; PATAI, 2010). E através de ações mais sutis de micromachismo, como interrupções na fala da entrevistada ou da pesquisadora por um homem (QUEMADA e PRIETO, 2005; ALPAY et al., 2010). Estas situações acabam por dificultar a pesquisa e colocam as envolvidas em situações desagradáveis e de insegurança pessoal. Nesse ensaio, nosso objetivo foi apresentar um conjunto de relatos de casos recolhidos entre o grupo de pesquisadoras do Laboratório de Ecologia Humana e Etnobotânica da Universidade Federal 
BLANCO, G. D. et al. Aprendizados nas entrelinhas: reflexões e olhares femininos no trabalho etnobiológico. Ethnoscientia v.6 n. 2, especial, 2021. DOI: 10.22276/ethnoscientia.v6i2.368

de Santa Catarina, ao longo de 10 anos de experiências em campo e fora dele, que ilustram olhares femininos no universo da pesquisa acadêmica. Através desses relatos, buscamos debater algumas das situações vivenciadas durante as pesquisas, e dar visibilidade às mulheres que encontramos em nossas trajetórias, que com sua presença, sua voz e perseverança buscam o estabelecimento de sociedades baseadas em relações sustentáveis com a natureza e com maior equidade e respeito entre os seres humanos.

\section{MATERIAIS E MÉTODOS}

Realizamos uma coletânea das experiências vivenciadas por diferentes pesquisadoras do Laboratório de Ecologia Humana e Etnobotânica, de Santa Catarina, com comunidades tradicionais no sul e sudeste do Brasil. Os relatos apresentados são frutos de pesquisas com povos indígenas, comunidades quilombolas, pescadores, agricultores tradicionais, assentamentos e comunidades locais. Os trabalhos de campo seguiram os procedimentos éticos e legais associados à pesquisa etnobiológica e os métodos usuais na coleta de dados, incluindo entrevistas semiestruturadas, observação e metodologias participativas. As experiências vivenciadas ocorreram entre os anos de 2009 e 2019, durante o mestrado e doutorado das pesquisadoras. Os relatos e reflexões que apresentamos nesse texto refletem os aprendizados que tivemos nas entrelinhas do nosso trabalho de campo, cujas perguntas específicas eram direcionadas aos objetivos de cada estudo.

Ao todo foram compiladas as experiências vivenciadas junto acerca de 350 entrevistas realizadas ao longo de dez anos, em comunidades tradicionais. Os relatos foram divididos em seis temas principais que marcaram as pesquisadoras: 1) Micromachismos; 2) Reafirmando nossa capacidade como pesquisadoras; 3) A pesca como uma prática masculina ou uma imposição; 4) A resistência da mulher negra; 5) Plantas medicinais enquanto um saber feminino, ou não?; e 6) Força de uma liderança rural.

\section{RESULTADOS}

Os relatos que serão apresentados foram realizados por diferentes pesquisadoras, em diferentes épocas e com comunidades tradicionais distintas, mas todas apresentaram um fator em comum: os desafios que existem devido à desigualdade de gênero. 
BLANCO, G. D. et al. Aprendizados nas entrelinhas: reflexões e olhares femininos no trabalho etnobiológico. Ethnoscientia v.6 n. 2, especial, 2021. DOI: 10.22276/ethnoscientia.v6i2.368

\subsection{Micromachismo, como me posicionar? (D. Cantelli)}

Vivenciei ações de machismo e micromachismo, direta e indiretamente ao longo dos trabalhos de campo que realizei em comunidades quilombolas de Santa Catarina e Rio Grande do Sul e agricultura familiar no Rio Grande do Sul.

Micromachismos são atitudes "invisíveis" presentes na normalização de expressões machistas (MENDÉZ, 1998), e essas fizeram parte da minha rotina. Por exemplo, quando eu enxerguei a intimidação com as filhas e mulheres que prestavam os serviços do lar tanto pela própria mulher quanto pelo homem-, ou quando vi a opinião da mulher sendo ridicularizada, abafada ou questionada pelos homens, ou, em casos mais constrangedores, quando os homens eram agressivos na fala, quando elas os questionavam ou enfrentavam, e, em alguns momentos, até no afeto e atenção de nossa parte com os entrevistados, tivemos que ser cautelosas, para evitar olhares maliciosos e piadas discriminatórias. Vivenciei estas mesmas situações na minha vida pessoal, porém, como agir quando estamos na nossa postura profissional de pesquisadoras, vinculadas a uma instituição? Os códigos de ética, a literatura e as disciplinas de etnobiologia me ensinaram a minimizar minha interferência nas comunidades, pois sou uma pessoa externa ao cotidiano e à cultura dessas. Então, como lidar com o desafio de conduzir a pesquisa acadêmica sem que os meus valores, ética e sentimentos pessoais interfiram?

Nesses momentos tentei passar um pouco do que acreditava, sempre com muito cuidado para não ofender nenhuma das partes. Mesmo com um sentimento abafado, utilizei de piadas ou conversas reflexivas, evitando ao máximo gerar discussões, pois iam contra meus princípios e valores éticos profissionais. Isso, de longe, não é o suficiente, mas é o resultado do conflito interior - nos trabalhos de campo, qual postura devo ter diante de uma situação que entendo como machismo?

\subsection{Reafirmando nossa capacidade como pesquisadoras (S.M.B. Cunha)}

Em minhas entrevistas na Baía Babitonga, no litoral norte de Santa Catarina, também vivenciei situações de machismo e micromachismo. O interessante é que esta baía traz em sua forma geográfica o formato de útero, um local que gera e nutre, não só o ecossistema como um todo, mas também os pescadores artesanais que dela dependem para manutenção da sua cultura e segurança alimentar.

Trabalhei em três comunidades pesqueiras, mas uma delas em particular me chamou atenção devido à presença de mulheres pescadoras e catadoras de crustáceos e moluscos que possuíam tanto conhecimento quanto os homens. Em uma situação, eu conversava com 
uma pescadora muito conhecida da comunidade e estávamos combinando a saída do dia seguinte para catar caranguejo para minhas amostras da pesquisa. $\mathrm{O}$ irmão da pescadora estava escutando a nossa conversa e fomos interrompidas por risos e deboches por parte dele, falando para a sua irmã não se iludir que eu (pesquisadora) não iria aparecer para a coleta, ressaltando que eu não sujaria as mãos no mangue para estragar o esmalte. Para não faltar com respeito, mas para também não deixar sem resposta, falei rindo e brincando que ele iria se surpreender comigo. O que mais me marcou nessa situação não foram os risos de deboche ou as palavras amargas me diminuindo, mas a preocupação e acolhimento da pescadora. Ela disse para eu não ligar para o que seu irmão estava falando e que por se tratar da primeira vez que eu iria pegar caranguejo, que não ficasse triste se não pegasse nada. Com essa excelente professora, aprendi rápido e pude capturar os caranguejos que precisava. Ao retornar ao porto, o irmão dela estava lá e logo começou a nos subestimar. A pescadora, toda orgulhosa, não perdeu tempo para contradizê-lo. O desfecho foi positivo, e o episódio mudou a forma com que eu passei a ser tratada por esse pescador. Porém, me incomoda saber que em uma atividade na qual predominam os homens, nós, mulheres, temos que nos reafirmar e mostrar competência para sermos respeitadas e que as mulheres pescadoras passam por isso frequentemente.

\subsection{O saber da pesca, uma prática naturalmente masculina ou uma imposição? (B.Silva)}

Trabalhar no município de Laguna, em Santa Catarina, com a pesca cooperativa entre pescadores e botos, foi uma experiência interessante. Uma atividade rara, praticada apenas por homens - até onde eu pude acompanhar - que dura mais de um século e que representa uma interação única entre o ser humano e o ambiente. Diariamente homens de diversas idades vão até a praia da Tesoura e por ali esperam a chegada dos botos-nariz-degarrafa (Tursiops truncatus). Os pescadores aguardam em vagas enfileiradas às margens do canal lagunar à espera dos botos, que por sua vez, parecem conduzir cardumes em direção aos pescadores (PETERSON et al. 2008). No início, por não haver nenhuma presença feminina no local, achei que minha presença pudesse intimidá-los, porém, durante a coleta de dados tive apenas uma recusa de entrevista. Entre conversas informais e entrevistas, escutei muitas piadas e brincadeiras em relação a ser mulher e também pesquisadora, mas não quis contrariá-los pois não queria que houvesse problemas futuros.

Durante as entrevistas, quando eu questionava sobre passarem este conhecimento sobre a pesca com botos para as gerações futuras, os pescadores respondiam que os filhos não tinham mais interesse hoje. Alguns pescadores afirmaram que não ensinavam essa 
prática por ter "apenas" filhas. Os únicos momentos em que observei a presença feminina na pescaria foi das mulheres que vendiam os peixes capturados por seus maridos, enquanto o homem continuava pescando. Outras mulheres de pescadores apenas iam até o local com seus filhos para assistir o marido pescar com os botos. Uma das poucas mulheres com quem pude conversar me disse que estar ali era por diversão e que muitas outras iam para dar apoio aos maridos.

Eu senti que ser mulher pesquisadora em meio a tantos homens é sentir insegurança e medo, porém, mesmo em um ambiente machista, fui sempre bem recebida. Meu trabalho era sobre a cooperação na pescaria, mas a conversa nunca era só sobre a pesca, era também sobre suas infâncias, sua família, o efeito do aquecimento global na safra e sobre a questão política do país. A cada entrevista fui percebendo que ser pesquisadora e estudar a cultura da pesca artesanal é uma maneira de fazer com que esses pescadores se sintam escutados, acolhidos e valorizados.

\subsection{A resistência da mulher negra na pesquisa e nos saberes (M.C. Gonçalves)}

A história das mulheres com as plantas é tão antiga quanto a própria existência humana, uma conexão tão intrínseca, que até divindades de várias culturas relacionadas à agricultura são representações femininas. Conheci durante minha jornada na ciência e nos estudos etnobotânicos algumas histórias de resistência e esperança de agricultoras e sua relação com a terra. Ao observar situações relacionadas ao lugar de fala ocupados por mulheres negras, incluindo aqui, as minhas próprias experiências, observei tantas estratégias para transpassar a invisibilidade e o silenciamento históricos e tomar o protagonismo, que me fizeram e fazem acreditar que não aceitaremos retrocessos, mesmo diante de um sistema que nos mata todo dia.

Em Iperó, interior de São Paulo, conheci uma agricultora do Assentamento Bela Vista, que a partir do envolvimento com a Organização Social Unidos Venceremos encontrou forças para voltar a estudar e organizar outras agricultoras na divisão do trabalho das propriedades. Numa realidade onde a maioria das mulheres são chefes de família, elas perceberam que a jornada dupla não era mais necessária e instituíram um calendário agrícola com atividades domésticas e de cuidado que antes estavam implícitas a funções de gênero. Houve grandes dificuldades na implementação tanto na percepção do tempo gasto por tarefas rotineiras, como no empenho para realização das tarefas; mas foi unânime para mulheres o reconhecimento dos familiares pelas atividades realizadas por elas. 
Muitas vezes notei que estas mulheres (quilombolas, assentadas, seringueiras) guardavam sua opinião em reuniões ou conversas em grupo, mesmo sendo contrárias ao que estava sendo dito. Para além do respeito às tradições, o machismo velado silencia suas vozes, mas não seus olhares e percepções. É notável quando estamos juntas somente entre mulheres e suas plantas, que a sabedoria brota nos detalhes que não se enxergavam, as plantas que pareciam espontâneas no entorno da casa aos poucos me mostram que na verdade não estão ali por acaso. De maneira detalhada me falam dos cuidados, usos, causos, precauções e, a partir desse momento, mudo completamente meu olhar sobre aquele lugar.

Frente às mulheres negras guardiãs de conhecimentos, ressignifico a serenidade no olhar de cada uma, que não está ligada à passividade e sim à sua resiliência, sabedoria e aos valores afro-civilizatórios vindos de antes da diáspora e que permitiram a sobrevivência, a permanência e a continuidade da vida, das pessoas e da agricultura no continente americano. Apesar de toda falta de estímulos e marginalidade dada aos seus saberes, muitas mulheres negras estão se fortalecendo, a pequenos passos e coletivamente, se reconhecendo e divulgando suas histórias de resistência e esperança, são vozes dissonantes que têm conseguido produzir rachaduras na estrutura hegemônica de poder.

\subsection{Plantas medicinais enquanto um saber feminino - ou não? (G.D. Blanco)}

Ao iniciar uma pesquisa junto com comunidades tradicionais, a cultura, a linguagem e o comportamento social são alguns dos desafios que encontrei, ainda mais sendo uma jovem pesquisadora. Sendo mulher, senti que mais um desafio era necessário superar: o machismo. Comecei a me aproximar das comunidades Guarani quando eu tinha 21 anos de idade e estava no meio da minha formação como bióloga. Eu nunca antes tinha visitado uma comunidade indígena e este contato mudou não apenas a minha visão como pesquisadora, mas a minha visão de mundo. Primeiro, eu tive que superar vários préconceitos sobre comunidades indígenas, alguns impostos pelos nossos próprios livros de história, depois me deparei com um mundo bem diferente do meu, mas com ligações profundas com outras experiências que eu já havia vivenciado na minha vida particular. Tanto na minha graduação como no meu mestrado, eu estudei a ligação dos Guarani com as orquídeas. No início da pesquisa, ao buscar as pessoas-chave sobre o conhecimento das orquídeas, surgiram indicações de homens como os detentores desses conhecimentos. Entretanto, ao realizar as entrevistas, passei a observar que o conhecimento vinha, muitas vezes, das suas esposas ou mães. Mas este fato não era percebido nem pelos homens nem pelas mulheres, pois mesmo as mulheres indicavam outros homens como detentores do 
conhecimento. Refleti sobre várias questões, como: Até que ponto o que eu vejo pode ser entendido como machismo ou apenas um comportamento cultural? Até que ponto não estou julgado outra cultura com a minha visão inexperiente, influenciada pela minha cultura e vivência pessoal?

No meu doutorado, um pouco mais madura, mas ainda com dúvidas e ainda sem resolver o que era machismo, me envolvi com comunidades mineradoras de Santa Catarina, para estudar o uso de plantas medicinais e alimentícias em áreas contaminadas pela mineração. Ao chegar nas casas para fazer as entrevistas, mesmo quando algum homem me atendia, era comum ele chamar uma mulher para responder. Em diversos momentos, enquanto a mulher era entrevistada, o homem ou a interrompia ou desvalorizava o conhecimento dela. Algumas vezes ouvi que o trabalho que eu fazia não tinha fundamento por se basear "apenas" no que era dito pelas mulheres. No entanto, os resultados do meu estudo mostraram que tanto homens como mulheres citaram o mesmo conjunto e número de espécies. Com esta situação, me deparei com um novo questionamento: como a sutileza dos papeis sociais e suas relações com os conhecimentos sobre plantas podem realmente ser acessados em profundidade, e o quanto esses conhecimentos estão mediados pelas discriminações de gênero e micromachismos?

\subsection{Força de uma liderança rural (S. Zank)}

A experiência de conviver e atuar em uma comunidade com uma luta histórica pela terra marcou profundamente a minha trajetória pessoal e acadêmica. Os Areais da Ribanceira é uma região tradicionalmente ocupada por agricultores e pescadores, que utilizam a área de forma comunitária, através do cultivo itinerante e da extração de produtos vegetais como o butiá e as plantas medicinais. Iniciamos a nossa pesquisa com o intuito de registrar os conhecimentos tradicionais e auxiliar no processo de reconhecimento desta comunidade enquanto tradicional, o que era importante para a sua luta pelo território. Entre muitos aprendizados com esta experiência nos Areais, destaco a vivência com uma liderança feminina, que me ensinou muito sobre a força das mulheres rurais. Uma dessas lideranças natas, mulheres destemidas que fazem o que precisa ser feito. Quando a conhecemos, ela tinha uma filha pequena, e se dividia entre a luta comunitária, seu trabalho e a família. Nos dois anos em que eu estive mais envolvida com a comunidade, talvez tenham sido os momentos mais tensos desta luta, que acabou gerando a desapropriação e a perda de parte do território, mas que nunca os fez perder a esperança e a fé em sua causa. No verão de 2010 ficamos imersos na comunidade realizando oficinas participativas e 
entrevistas. Neste período havia informações de que parte da área que era utilizada pela comunidade seria revertida para um quarentenário de gado, e para evitar esta perda a liderança passou a fazer articulações com instituições parceiras (Universidade, INCRA, ICMBio, MST, entre outras). Em uma reunião com o MST, eles foram surpreendidos com uma ação policial que levou a liderança e os demais líderes do MST presos sob a acusação de formação de quadrilha. Ela estava grávida de três meses e ficou alguns dias presa em uma delegacia, o que gerou muita revolta e medo. Eu sentia que aquele ato era extremamente injusto e insensível, ao colocar uma mulher grávida presa por defender o bem-comum, um espaço coletivo de cultivo. Representava não apenas um desrespeito pelas comunidades locais, pelas mulheres, mas também pela vida. Ela foi firme e imbatível e lembro de perceber a força daquela mulher e pensar se eu seria capaz de fazer o mesmo. A comunidade, por outro lado, já via aquela criança que se desenvolvia no ventre de sua mãe como um grande guerreiro, que dava força para sua mãe continuar resistindo. E foi isso que aconteceu, pois esta mulher não se intimidou e continuou ocupando o seu lugar, na defesa do bem-comum. Assim como ela, muitas mulheres escutam o chamado da "mãe Terra", e simplesmente fazem o que precisa ser feito para defender o bem-comum e o bem-viver. A construção de uma sociedade com maior equidade só será possível com a presença das mulheres nos espaços de liderança e de tomada de decisão. Mas por que ainda existe tanta resistência das mulheres assumirem espaços de poder? De que forma podemos ampliar esta discussão nos espaços acadêmicos?

\section{DISCUSSÃO}

Nos relatos aqui compilados podemos observar que algumas dificuldades e desafios se reproduzem, independente do contexto, tais como a invisibilidade das atividades e saberes femininos, múltiplas jornadas de trabalho, força e luta da mulher, resistência, resiliência e união feminina. Ao falarmos sobre desigualdades de gênero estamos debatendo, também, sobre como estas assimetrias são refletidas dentro dos contextos de produção de conhecimentos, sejam eles acadêmicos ou conhecimentos locais/tradicionais, baseados nos valores de uma sociedade patriarcal que urgem em ser questionados, e que podem dificultar uma compreensão profunda dos conhecimentos tradicionais e da atuação das pesquisadoras.

As desigualdades de gênero, evidenciadas por práticas como machismo e micromachismo, não são temas recentes (GONZALEZ, 2014). O machismo, compreendido como um sistema de ideias e valores que reforça e legitima o preconceito e as diferenças 
entre os gêneros, se baseia em uma visão errônea que surgiu com o "naturalismo" e que defende a "pseudonatureza" superior do homem sobre a mulher (WELZER-LONG, 2001; GONZALEZ, 2014). Esta situação intensifica problemas centrais da desigualdade entre os gêneros, como, por exemplo, o que é "ser homem" ou o que é "ser mulher", associando este "ser" a papeis sociais pré estabelecidos que limitam, prejudicam ou mesmo impedem a expressão de outros papéis (WELZER-LONG, 2001). Essas construções sociais afetam também a forma de fazer pesquisa, pois, por exemplo, podem embasar as entrevistas com visões estereotipadas pré-estabelecidas: será que vincular a mulher às questões alimentares já não é um pré-julgamento de um papel esperado? É importante ter esses questionamentos em mente para evitar uma barreira pré-estabelecida que nos impeça de compreender as relações complexas e profundas das pessoas com o meio a sua volta.

Debater a desigualdade sobre gêneros também é debater a história da humanidade como um todo, e os diversos olhares culturais que existem sobre este tema (MATURANA, 2004). Em diferentes sociedades humanas, sejam ancestrais ou atuais, a Terra está associada ao feminino, um aspecto que gera a nutrição, o cuidado e que sustenta a vida (MATURANA, 2004). A vinculação das mulheres com as práticas associadas a este elemento, como de alimentação e cuidados da saúde, é presente em muitas culturas do mundo (VOEKS, 2007; TORRES-AVILEZ et al., 2016). A compreensão do uso da terra enquanto um bem-comum, para usufruto com equidade para as presentes e futuras gerações, está ligado a aspectos deste feminino ancestral que de alguma forma habita a todos nós, independente do gênero. Porém, como observado nos relatos apresentados, ainda há muito a avançar no respeito e reconhecimento a esses saberes, dentro e fora das comunidades tradicionais.

A desigualdade de gênero, reforçada em uma lógica heterocisnormativa (BORGES et al., 2013), também foi fomentada pelo capitalismo, que atua através da dominação de uma classe sobre a outra, para que o seu sistema funcione, mesmo que isso acentue as desigualdades (FEDERICI, 2016). Esta situação é escancarada quando observamos a desigualdade nas pautas e lutas de diferentes mulheres (DESCARRIES, 2000; PATAI, 2010). Ao observarmos e vivenciarmos desigualdades tanto nas comunidades tradicionais ou na academia, devemos olhar também para este sistema que atua como pano de fundo e influência na pluralidade das lutas que fazem frente às desigualdades de gênero (DESCARRIES, 2000; PATAI, 2010). Quando falamos das lutas das mulheres negras e indígenas, estas partilham de processos de resistência nos quais as experiências de escravidão, racismo e colonialismo deixaram marcas profundas, mas que também as 
BLANCO, G. D. et al. Aprendizados nas entrelinhas: reflexões e olhares femininos no trabalho etnobiológico. Ethnoscientia v.6 n. 2, especial, 2021. DOI: 10.22276/ethnoscientia.v6i2.368

levaram a transcender e fortalecer a sua identidade (GONZALES, 1988). Dados, como o do IBGE (Instituto Brasileiro de Geografia e Estatística) e do IPEA (Instituto de Pesquisa Econômica e Aplicada) apontam que as mulheres negras apresentam as piores condições de trabalho, de salários, e os postos de trabalho mais precarizados e com maior vulnerabilidade social (MARCONDES et al., 2017). Em 1970 se fortaleceu no Brasil, o Movimento de Mulheres Negras (MMN), a partir da percepção de que faltava o debate conjunto sobre gênero e raça nos movimentos sociais da época (COELHO e GOMES, 2015). Pois, os direitos das mulheres negras não eram devidamente tratados nem pelo movimento negro e nem pelo movimento feminista nacional. Como destaca Djamila Ribeiro (2019), no Brasil temos que ter um movimento social que lute contra preconceitos e discriminações que as mulheres negras passam, tanto de gênero como de raça. E estes debates devem chegar em diversas áreas da sociedade, como nas comunidades tradicionais e nos centros de pesquisa.

Assim como as mulheres negras, nos grupos indígenas, a herança do colonialismo ainda é um fator de grande influência na desigualdade de gêneros. Entretanto, ainda que não possamos de forma alguma generalizar este grupo tão diverso - com particularidades culturais em cada etnia - historicamente e culturalmente há uma maior equidade de gênero nestes grupos em comparação com as sociedades ocidentais (PINTO, 2010). Segundo Gonzalez e Hasenbalg (1982) e Pinto (2010), práticas machistas em diferentes grupos indígenas foram intensificadas ou surgiram com a chegada dos colonizadores europeus, e são ainda mais evidenciadas com o avanço sobre suas terras e culturas, que marginalizam estes grupos e triplicam os desafios da mulher indígena, como por exemplo, ao gerar pobreza nas comunidades (GONZALEZ e HASENBALG, 1982; PINTO, 2010). O surgimento de lideranças femininas nas políticas indígenas também foi influenciado por movimentos feministas que vieram de fora das comunidades indígenas, e hoje têm ganhado mais espaço entre os povos da América latina (PINTO, 2010) e em outros espaços de representatividade. Atualmente, encontramos grupos como o Fagtar, formado por mulheres indígenas e não indígenas, que buscam por espaços de diálogo e reconhecimentos pelos direitos e diminuição da invisibilidade da mulher indígena, no passado e presente, do Brasil (MACHADO e KAIGANG, 2020). Em 2019 este grupo organizou o $1^{\circ}$ Fórum e $1^{\text {a }}$ Marcha das Mulheres Indígenas do Brasil em Brasília, em que foi cobrado do governo brasileiro maior reconhecimento e direitos da mulher indígena (FAGTAR, 2020).

Os papéis pré-estabelecidos associados aos gêneros também contribuem para a invisibilidade da atuação da mulher em algumas práticas tradicionais, como, por exemplo, as atividades pesqueiras. Nessas atividades, geralmente o trabalho da mulher é 
BLANCO, G. D. et al. Aprendizados nas entrelinhas: reflexões e olhares femininos no trabalho etnobiológico. Ethnoscientia v.6 n. 2, especial, 2021. DOI: 10.22276/ethnoscientia.v6i2.368

menosprezado e ou considerado apenas como uma extensão de suas responsabilidades domésticas (HARPER et al., 2017). Mesmo que essas mulheres atuem desde o processo de captura, beneficiamento e venda, ainda são negligenciadas (HARPER et al., 2013). Estimativas sugerem que $47 \%$ das pessoas que trabalham em diferentes atividades pesqueiras no mundo são mulheres (WORLD BANK, 2012), porém, essas contribuições são subrepresentadas nas estatísticas oficiais e se tornam invisíveis à sociedade.

Como pesquisadoras na área da etnobiologia, sugerimos que todos os etnobiólogos, independente de seu gênero ou identidade, voltem seus olhares para a importância das mulheres nas comunidades tradicionais e nos ambientes acadêmicos. A etnobiologia, por ser uma área de conhecimento que ocorre em interface com diferentes culturas e modos de viver, possui o potencial de questionar as relações de poder estabelecidas por uma sociedade. Mas, também, precisa debater sobre as condutas para fazer frente ao machismo, micromachismo, e às desigualdades de gênero, além de criar pontes de diálogos e oportunidades para que estas mulheres em comunidades tradicionais sejam protagonistas de suas próprias histórias. Por fim, gostaríamos de pontuar algumas questões que precisam ser consideradas no âmbito da pesquisa etnobiológica, de forma a contribuirmos para relações de maior equidade dentro e fora da academia. Devemos reconhecer a existência de diferentes lutas feministas dependendo da classe social, raça, etnia: precisamos escutar as vozes de todas as mulheres e cuidar ao falar por elas. Devemos dar visibilidade ao que passamos; e reconhecer que o machismo está presente em muitas comunidades e na academia e, desta forma, precisamos nos proteger e nos unir. Devemos discutir como nossos projetos podem colaborar para uma abordagem de gênero mais emancipatória com as comunidades locais. Devemos demandar o apoio e proteção das instituições para a atuação das pesquisadoras em locais em que suas vidas possam estar ameaçadas. Devemos reconhecer que gênero é uma construção cultural, e que se estiver baseada em relações de desigualdades e opressão, precisa ser modificada. Não podemos nos limitar ao que nos é imposto culturalmente sobre ser mulher afinal: Lugar de mulher é onde ela quiser!

\section{AUTORIZAÇÕES ÉTICAS}

Todas as pesquisas obtiveram os termos de Consentimento Livre e Esclarecido, assim como as devidas autorizações do Comitê de ética (80660217.1.0000.0121, 06457419.6.0000.0121, 18847013.0.0000.0121, 0660217.1.0000.0121), FUNAI (Ofício n ${ }^{\circ}$ 261/2016) e ICMBio. 
BLANCO, G. D. et al. Aprendizados nas entrelinhas: reflexões e olhares femininos no trabalho etnobiológico. Ethnoscientia v.6 n. 2, especial, 2021. DOI: 10.22276/ethnoscientia.v6i2.368

\section{AGRADECIMENTOS}

As autoras agradecem a todas as entrevistadas e lideranças mulheres das comunidades tradicionais, por terem compartilhado conosco as suas experiências de vida, conhecimentos, lutas e força.

\section{REFERÊNCIAS BIBLIOGRÁFICAS}

ALPAY, E. H. KAMBOURI, M. AHEARN, A. L. Gender issues in the university research environment. European Journal of Engineering Education, v. 35, p. 135-45, 2010.

BAUER, G. 'What is wrong with a woman being chief?' Women chiefs and symbolic and substantive representation in Botswana. Journal of Asian and African Studies, v. 51, p. 222-237, 2016.

BORGES, Z. N. FÁtimA C. V. PERURENA, G. R. P. MURIEL, B. Patriarcado, heteronormatividade e misoginia em debate: pontos e contrapontos para o combate à homofobia nas escolas. Latitude 7, v. 1, p. 61-76, 2013.

CAPES. Mulheres são maioria na Pós-Graduação brasileira. 2017. Disponível em: $<$ https://www.capes.gov.br/36-noticias/8315-mulheres-sao-maioria-na-pos-graduacaobrasileira>. Acesso em: 07 de maio de 2020.

COELHO, A. M. S. GOMES, S. S. O movimento feminista negro e suas particularidades na sociedade brasileira. VII Jornada Internacional de Políticas Públicas, n. 1, p. 1-10, 2015.

DA SILVA, T. C. DE MEDEIROS P. M. HANAZAKI, N. DA FONSECA-KRUEL, V. S. HORA, J. S. L. DE MEDEIROS, S. G. The role of women in Brazilian ethnobiology: Challenges and perspectives. Journal of Ethnobiology and Ethnomedicine, v. 15, p. 1-11, 2019.

DESCARRIES, F. Teorias feministas: liberação e solidariedade no plural. Textos de História, v. 8, p. 9-45, 2000.

FAGTAR. Marcha das Mulheres Indígenas: Território: nosso corpo, nosso espírito. 2020. Disponível em: <https://fagtar.org/>. Acesso em: 10 de set. de 2020.

FEDERICI, S. Calibã e a Bruxa: mulheres corpo e acumulação primitiva. 2. ed. São Paulo: Elefante, 2016. 464 p.

FREITAS, M. A. PEREIRA, E. G. The inexpressive feminine representation in the Brazilian scientific academies and in the Nobel prize. Ex aequo, v. 36, p. 189-202, 2017.

GONZALES, L. A categoria político-cultural de amefricanidade. Tempo brasileiro, v. 92, n. 93, p. $69-82,1988$.

GONZALEZ, D. F. Entre público, privado e político: avanços das mulheres e machismo velado no Brasil. Cadernos de Pesquisa, v. 44, n. 151, p. 239-243, 2014. 
BLANCO, G. D. et al. Aprendizados nas entrelinhas: reflexões e olhares femininos no trabalho etnobiológico. Ethnoscientia v.6 n. 2, especial, 2021. DOI: 10.22276/ethnoscientia.v6i2.368

GONZALEZ, L.; HASENBALG, C. Lugar de Negro. 2. ed. Rio de Janeiro: Editora Marco Zero, 1982. 115p.

GUEDES, M. C. Women's presence in undergraduate and graduate courses: deconstructing the idea of university as a male domain. História, Ciências, Saúde, Rio de Janeiro, v. 15, p. 117-132, 2008.

HARPER, S. ZELLER, D. HAUZER, M. PAULY, D. SUMAILA, U. R. Women and fisheries: Contribution to food security and local economies. Marine Policy, v. 39, p. 5663, 2013.

HARPER, S. GRUBB, C. STILES, M. SUMAILA, U. R. Contribuitions by Women to Fisheries Economies: Insights from Five Maritime Contries, Coastal Management, v. 45, n. 2, p. 91-106, 2017.

MACHADO, J. S. KAINGANG, J. D. A força delas: abrindo caminho. Fagtar, v. 1, p. 1-9, 2020 .

MARCONDES, M. M. PINHEIRO, L. QUEIROZ, C. QUERINO, A. C. VALVERDE, D. (Org.). Dossiê mulheres negras: retrato das condições de vida das mulheres negras no Brasil. 1. ed. Editora Inpea, 2017. 168p.

MATURANA, H. R. Conversações matrísticas e patriarcais. In: MATURANA, H. R., VERDEN-ZOLLER, G. Amar e brincar: fundamentos esquecidos do humano - do patriarcado à democracia. 3. ed. São Paulo: Palas Athena, 2004. 75p.

MENDÉZ, L. B. Micromachismos, la violencia invisible. Madrid: Cecom, 1998. 119 p. NOGUEIRA, M. C. O. C. Os discursos das mulheres em posição de poder. Cadernos de Psicologia Social do Trabalho, v. 2, n. 9, p. 57-72, 2006.

ONU. Objetivos de desenvolvimento sustentável. 2015. Disponível em: $<$ https://nacoesunidas.org/pos2015/>. Acesso em: 10 de set. de 2020.

PATAI, D. Do feminismo, aos seus plurais. Revista Estudos Feministas, v. 20, p. 313$337,2010$.

PETERSON, D. HANAZAKI, N. SIMOES-LOPES, P. C. Natural resource appropriation in cooperative artisanal fishing between fishermen and dolphins (Tursiops truncatus) in Laguna, Brazil. Ocean \& Coastal Management, v. 51, n. 6, p. 469-475, 2008.

PINTO, A. A. Reinventando o feminismo: as mulheres indígenas e suas demandas de gênero. Diásporas, Diversidades e Deslocamentos, p. 1-10, 2010.

QUEMADA, C. PRIETO, P. La violencia contra las mujeres: prevención y detección. 1. ed. Madrid: Editora Diaz de Santos, 2005. 312 p.

RIBEIRO, D. Lugar de fala. 1. ed. São Paulo: Editora Pólen, 2019. 128p. 
BLANCO, G. D. et al. Aprendizados nas entrelinhas: reflexões e olhares femininos no trabalho etnobiológico. Ethnoscientia v.6 n. 2, especial, 2021. DOI: 10.22276/ethnoscientia.v6i2.368

TAI, S.H.T. e BAGOLIN, I.P. Regional Differences in the Gender Earnings Gap in Brazil: Development, Discrimination, and Inequality. The Developing Economies, v. 57, p. 55-82, 2019.

TORRES-AVILEZ, W. S. MEDEIROS, P. M. ALBUQUERQUE, U. P. Effect of gender on the knowledge of medicinal plants: systematic review and meta-analysis. Hindawi Publishing Corporation, p. 1-13, 2016.

VIEIRA, B. Mulheres negras no Brasil: trabalho, família e lugares sociais. 2018. 107. Dissertação de mestrado (Antropologia) - Programa de Pós-Graduação em Antropologia, Universidade Estadual de Campinas, Campinas.

VOEKS, R. A. Are women reservoirs of traditional plant knowledge? Gender, ethnobotany and globalization in northeast Brazil. Singapora Journal of Tropical Geography, v. 28, p. 7-20, 2007.

WELZER-LONG, D. A. A construção do masculino: dominação das mulheres e homofobia. Revista Estudos Femininos, v. 2, p. 460-482, 2001.

WORLD BANK. Hidden harvest: The global contribution of capture fisheries. In: INTERNATIONAL BANK FOR RECONSTRUCTION AND DEVELOPMENT. 2012, Washington, D.C. 